\title{
MIP nanoparticles in diagnostics and bioimaging
}

\author{
Sergey A. Piletsky \\ Chemistry Department \\ College of Science and Engineering \\ University of Leicester \\ LE1 7RH \\ E: sp523@le.ac.uk
}

Two years ago we have made a major breakthrough in MIP technology developing solid-phase approach for preparation of soluble molecularly imprinted nanoparticles (nanoMIPs) with exquisite affinity and selectivity for their templates ${ }^{1}$. The success came from combining controlled radical polymerisation ${ }^{2}$ with an affinity separation step performed on surface-immobilised template ${ }^{3}$. This approach represents the state-of-the-art in nanoMIP synthesis: not only are soluble particles with defined size $(20-200 \mathrm{~nm})$ and a narrow size distribution produced in one hour, they possess subnanomolar dissociation constants for their respective targets, they can be easily functionalised with fluorescent, electrochemical or magnetic labels, and the immobilised template can be re-used. High affinity nanoMIPs were made for small molecules, proteins, membrane proteins and virus particles ${ }^{4}$.

The main practical niches for application of synthesised nanoMIPs are diagnostics, imaging and drug delivery. Particularly exciting is an opportunity to use MIP sensors in companion diagnostics. Members of our team have used nanoMIPs successfully as a replacement for antibodies in ELISA-type assays, electrochemical and optical sensors ${ }^{5}$. The exciting examples of our work with in vivo application potential are targeting membrane receptors, enzymes and quorum sensing molecules ${ }^{6}$. Very encouraging facts that enables practical applications of MIPs in vivo are lack of polymer toxicity, ability of nanoMIPs to penetrate into cells and to pass blood barrier. Current paper discusses challenges and opportunities that are faced by MIP technology in the light of these developments.

\section{References}

[1] Poma A., Guerreiro A., Whitcombe M. J., Piletska E., Turner A. P. F., Piletsky S. (2013). Solid-phase synthesis of molecularly imprinted polymer nanoparticles with a reusable template ("plastic antibodies"). Adv. Functional. Mater., 23: 2821-2827.

[2] Subrahmanyam S., Guerreiro A., Poma A., Moczko E., Piletska E., Piletsky S. (2013). Optimization of experimental conditions for synthesis of high affinity MIP nanoparticles. Eur. Polym. J., 49: 100-105.

[3] Guerreiro A. R., Chianella I., Piletska E., Whitcombe M. J., Piletsky S. A. (2009). Selection of imprinted nanoparticles by affinity chromatography. Biosens. Bioelectron., 24: 2740-2743.

[4] Altintas Z., Gittens M., Guerreiro A., Thompson K.-A., Walker J., Piletsky S., Tothill I. E. (2015). Detection of waterborne viruses using high affinity molecularly imprinted polymers. Anal. Chem., 87: 6801-6807.

[5] Chianella I., Guerreiro A., Moczko E., Caygill J. S., Piletska E. V., Perez De Vargas Sansalvador I. M., Whitcombe M. J., Piletsky S. A. (2013). Direct replacement of antibodies with molecularly imprinted polymer (MIP) nanoparticles in ELISA - development of a novel assay for vancomycin. Anal. Chem., 85: 8462-8468.

[6] Guerreiro A., Poma A., Moczko E., Takarada J., Vargas-Sansalvador I. P., Turner N., Piletska E., Magalhães C. S., Glazova N., Serkova A., Omelianova A., Karim K., Piletsky S. (2014). Influence of surface-imprinted nanoparticles on trypsin activity. Adv. Healthcare Mat., 3: 1426-1429. 